\title{
Taguchi optimization and scale up of xylanase from Bacillus licheniformis isolated from hot water geyser
}

\author{
Girisha Malhotra and Shilpa S. Chapadgaonkar* (1)
}

\begin{abstract}
Background: Xylanase is one of the widely applied industrial enzymes with diverse applications. Thermostability and alkali tolerance are the two most desirable qualities for industrial applications of xylanase. In this paper, we reveal the statistical Taguchi optimization strategy for maximization of xylanase production. The important process parameters $\mathrm{pH}$, temperature, concentration of wheat bran, and concentration of yeast extract were optimized using the Taguchi $L_{8}$ orthogonal array where the 4 factors were considered at 2 levels (high and low).

Results: The optimized conditions given by model were obtained as follows: (i) pH 6, (ii) culture temperature $35^{\circ} \mathrm{C}$, (iii) concentration of xylan $2 \% \mathrm{w} / \mathrm{v}$, (iv) concentration of wheat bran $2.5 \% \mathrm{w} / \mathrm{v}$. The production was scaled upto $2.5 \mathrm{~L}$ bioreactor using optimized process parameters. A high xylanase titer of $400 \mathrm{U} / \mathrm{ml}$ could be achieved in less than 60 $\mathrm{h}$ of culture in the reactor.

Conclusion: Optimization was successful in achieving about threefold increase in the yield of xylanase. The optimized conditions resulted in a successful scale up and enhancement of xylanase production.
\end{abstract}

Keywords: Xylanase, Feed enzyme, Taguchi design, Bacillus, Xylan

\section{Background}

Xylanase is widely used industrial enzyme, and the development of indigenous technologies is essential to improve the economy of the process applications. Microbial medium optimization is known to improve the bioprocess production yields by many folds $[1,5,10,16,19]$. The traditional one factor at a time (OFAT) medium optimization methodology requires too many optimization experiments and takes an unreasonable amount of time. The full factorial statistical optimization designs consider all the possible combinations of factors; a full factorial experimental design for " $n$ " factors to be tested at " $k$ " different levels needs " $n$ " experiments. Traditional process requires huge number of trial experiments and is tedious and time consuming. Moreover, since each factor is taken "one-at-a-time" interaction between the factors cannot be studied. In contrast,

\footnotetext{
*Correspondence: shilpas.fet@mriu.edu.in; shilpa.chap@gmail.com Department of Biotechnology, Manav Rachna International Institute of Research and Studies, Faridabad, Haryana, India
}

statistical optimization techniques like the Taguchi design can achieve optimization in smaller number of experiments. Optimization of four process parameters at two different levels would require $4^{2}$, i.e., 16 different experimental trials using the traditional one factor at a time full factorial design, whereas this optimization can be achieved in only 8 experimental trials with the Taguchi approach. Moreover, since the variables are optimized simultaneously, interaction between the factors, if any, can be identified. The Taguchi design considers two different types of factors: control factors (the factors that can be controlled) and noise factors (i.e., factors that cannot be controlled). The Taguchi method seeks to minimize the variation due to noise and to study the effect of independent variables. The orthogonal Taguchi design has been used extensively to optimize the process parameters for production of many enzymes including xylanases [6], tannase [13], alkaline protease [17], $\alpha$-amylase [21], and L-asparaginase [2].

\section{Springer Open}

(๑) The Author(s). 2020 Open Access This article is licensed under a Creative Commons Attribution 4.0 International License, which permits use, sharing, adaptation, distribution and reproduction in any medium or format, as long as you give appropriate credit to the original author(s) and the source, provide a link to the Creative Commons licence, and indicate if changes were made. The images or other third party material in this article are included in the article's Creative Commons licence, unless indicated otherwise in a credit line to the material. If material is not included in the article's Creative Commons licence and your intended use is not permitted by statutory regulation or exceeds the permitted use, you will need to obtain permission directly from the copyright holder. To view a copy of this licence, visit http://creativecommons.org/licenses/by/4.0/. 
In the present study, optimization of bioprocess for thermo-alkali stable xylanase production from a newly discovered Bacillus licheniformis isolate from the hot water geyser in Sohna, Haryana, India, was carried out with the objective of maximization of xylanase production. This isolate has been shown to possess high xylanolytic activity in our studies [15]. Optimization of four independent parameters with an objective to maximize xylanase production was carried out at two different levels.

\section{Methods}

\section{Microorganism and culture maintenance}

Prior to main trials for the optimization of the medium, the isolate $\mathrm{B} 2$, a bacterial strain with high xylanolytic potential was selected and was identified as a strain of Bacillus licheniformis [15]. It was maintained in nutrient agar medium at $\mathrm{pH} 7.0$ and temperature $35^{\circ} \mathrm{C}$. The glycerol stock cultures and working stock cultures were maintained as slants and revived regularly.

\section{Preparation of inoculum}

The seed culture was prepared by inoculating actively growing culture of the Bacillus licheniformis strain to 50 $\mathrm{ml}$ of nutrient broth supplemented with $1 \% \mathrm{w} / \mathrm{v}$ xylan and pH 6.5 in a 250-ml Erlenmeyer flask. The culture was incubated at $35^{\circ} \mathrm{C}$ with continuous shaking at 150 RPM.

\section{Culture medium}

The basal medium used consisted of $0.5 \% \mathrm{w} / \mathrm{v}$ yeast extract, $0.25 \% \mathrm{w} / \mathrm{v} \mathrm{NaCl}, 0.5 \% \mathrm{w} / \mathrm{v} \mathrm{NH}_{4} \mathrm{Cl}, 0.025 \% \mathrm{w} / \mathrm{v}$ $\mathrm{MgSO}_{4} 7 \mathrm{H}_{2} \mathrm{O}$, and $1 \% \mathrm{w} / \mathrm{v}$ of agricultural waste as the source of carbon in the medium. Available agro-residues: xylan, wheat bran, and sorghum stalk were procured locally. They were subjected to pretreatment, which lead to the softening and increased the accessibility of the complex carbon source. The pretreatment process involved cleaning, grinding for size reduction, sieving, and autoclaving with other medium components.

The trials for the selection of nitrogen source involved varying the type of nitrogen source (peptone, tryptone, and yeast extract and ammonium sulfate) and comparing the xylanase production in the medium. The basal medium used here was $0.5 \% \mathrm{w} / \mathrm{v}$ of nitrogen source, $0.25 \% \quad \mathrm{w} / \mathrm{v} \quad \mathrm{NaCl}, \quad 0.5 \% \quad \mathrm{w} / \mathrm{v} \quad \mathrm{NH}_{4} \mathrm{Cl}, \quad 0.025 \% \quad \mathrm{w} / \mathrm{v}$ $\mathrm{MgSO}_{4} 7 \mathrm{H}_{2} \mathrm{O}$, and $1 \% \mathrm{w} / \mathrm{v}$ wheat bran with initial medium of 7.0. During these trials, all other factors were kept constant.

The medium was autoclaved at $121^{\circ} \mathrm{C}$ for $20 \mathrm{~min}$. Fifty milliliter of this formulated medium was taken in $250 \mathrm{ml}$ shake flask and inoculated with actively growing culture.

\section{Xylanase assay}

Xylanase activity was determined by 3, 5-dinitrosalicylic acid (DNSA) method. It depends on measuring the concentration of reducing sugars liberated from xylan by the activity of xylanase [3]. In brief, the culture broth was first centrifuged at $10,000 \mathrm{RPM}$ for $10 \mathrm{~min}$ at $10{ }^{\circ} \mathrm{C}$. One percent w/v beechwood xylan (Himedia MB14110G) prepared in $0.05 \mathrm{M}$ sodium citrate buffer $\mathrm{pH} 6.5$ was used as substrate. One milliliter of substrate was incubated with $500 \mu \mathrm{l}$ of crude enzyme (supernatant obtained from centrifuged culture broth) at $50{ }^{\circ} \mathrm{C}$ for 15 min. The reaction was terminated by the addition of 3 $\mathrm{ml}$ of DNSA reagent and the mixture was boiled for 10 min in a water bath. The absorbance was measured at $540 \mathrm{~nm}$; after cooling, the mixture which is a measure of reducing sugar liberated due to enzyme action. A calibration curve using xylose was determined with xylose as standard. One unit of xylanase activity $(\mathrm{U})$ is defined as the amount of enzyme that liberates $1 \mu \mathrm{mol}$ of reducing sugar-xylose per min under the standard assay conditions.

$$
\text { Xylanase activity } U / m l=\frac{\text { Absorbance at } 540 \mathrm{~nm} \times \text { Dilution factor }}{\text { Time of incubation } \times \text { volume of sample taken }}
$$

Taguchi design for optimization of xylanase production The important steps in the Taguchi design have been given schematically in Fig. 1. The generation of design L8 array and analysis of results were carried out using the Minitab ${ }^{\oplus}$ (trial version) software.

The optimization was carried out using $\mathrm{L}_{8}$ orthogonal array where the 4 factors were considered at 2 levels (high and low). The high and low values were chosen on the

\section{Selection of output parameter (xylanase activity obtained $\mathrm{U} / \mathrm{ml}$ )<smiles>C1CCCC1</smiles>

Selection of variables (input parameters)

1. Culture pH

2. Incubation Temperature

3. Concentration of wheat bran

4. Concentration of yeast extract<smiles>CCCC</smiles>

Choice of suitable orthogonal array<smiles>C[Al]C</smiles>

Assign factor values<smiles>C=IC</smiles>

Conduction of experiments

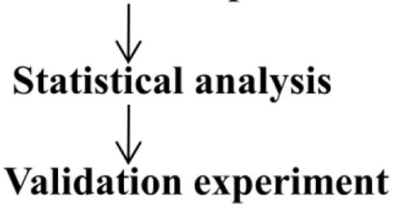

Fig. 1 Steps in statistical optimization using the Taguchi design 
basis of previous literature $[9,11,15]$. The factors considered in the optimization design were (i) concentration of wheat bran, (ii) $\mathrm{pH}$ (iii) culture temperature, and (iv) concentration of yeast extract. The factorial design used has been given in Table 1. During the trials, all other media components and process parameters were kept constant. Xylanase activity was measured as the "output parameter." All of the experiments were repeated three times for obtaining statistically significant results.

\section{Taguchi design analysis} Signal to noise ratio

In the Taguchi optimization, signal to noise $(\mathrm{S} / \mathrm{N})$ ratio is the ratio of desirable "signal" to the undesirable "noise" or variation. Therefore, it can be used to determine the design quality. Since our objective is to maximize the signal factor (xylanase activity). $\mathrm{S} / \mathrm{N}$ ratio for "larger the better" output was used. The effect of each factor was ranked according to its significance.

This was calculated as

$$
\mathrm{S} / \mathrm{N}=-10 * \log \left(\sum\left(1 / \mathrm{Y}^{2}\right) / \mathrm{n}\right)
$$

where

$\mathrm{S} / \mathrm{N}$ is the signal to noise ratio,

$Y$ is the signal factor (xylanase activity),

$n$ is the number of repetitions in the experiment.

\section{Main effects}

The main effect of each factor was calculated using the following equations.

$$
\begin{aligned}
& X 1(A)=(a+b+c+d) / 4=\operatorname{ME} 1(A) \\
& X 2(A)=(p+q+r+s) / 4=\operatorname{ME} 2(A)
\end{aligned}
$$

Where, $X 1(A)$ was the mean of the output value (xylanase activity) when the factor A was at level 1 and $X 2(A)$ was the mean of the factor A was at level 2. The mean value of $X 1(A)$ and $\mathrm{X} 2(A)$ in different runs was computed. Thus if a, b, c, d, p, q, r, s are the output

Table 1 Taguchi L8 array for 2-level 4-factors

\begin{tabular}{lllll}
\hline SN & \multicolumn{5}{l}{ Factors with assigned levels } \\
\cline { 2 - 5 } & $\mathbf{p H}$ & Temperature $\left({ }^{\circ} \mathbf{C}\right)$ & $\begin{array}{l}\text { Concentration } \\
\text { of wheat bran } \\
(\% \text { w/v) }\end{array}$ & $\begin{array}{l}\text { Concentration } \\
\text { of yeast extract } \\
(\% \text { w/v) }\end{array}$ \\
\hline 1 & 6 & 35 & 0.5 & 1 \\
2 & 6 & 35 & 2 & 2.5 \\
3 & 6 & 45 & 0.5 & 2.5 \\
4 & 6 & 45 & 2 & 1 \\
5 & 8 & 35 & 0.5 & 2.5 \\
6 & 8 & 35 & 2 & 1 \\
7 & 8 & 45 & 0.5 & 1 \\
8 & 8 & 45 & 2 & 2.5 \\
\hline
\end{tabular}

(xylanase activities) obtained in different runs where the factor A was at level 1 or level 2. The delta value of difference in the effects is obtained as

$$
\Delta=\mathrm{X} 1(A)-\mathrm{X} 2(A)
$$

The importance of each factor on xylanase activity was determined by its rank which is assigned on the basis of the relative delta value.

\section{Analysis of variance or ANOVA}

ANOVA was applied to determine the statistical significance of the results. The variance due to the factors or their combinations as well as the variation due to noise was determined. The test data points were used to calculate the total variance of the desired output. The measure of "relative significance" was based on an $F$ test. The factors having $p<0.05$ were identified as significant. After determination of optimal process parameters, validation experiments were carried out and the xylanase activity obtained in the validation experiments were compared with the values predicted by the model.

\section{Bioreactor studies}

The xylanase production was scaled up to laboratoryscale $5 \mathrm{~L}$ bioreactor (Bioage, India) with working volume of $4 \mathrm{~L}$. The bioreactor possessed the automated systems to control and monitor dissolved the oxygen (DO), $\mathrm{pH}$, agitator, temperature, and foaming. The $\mathrm{pH}$ electrode was first calibrated using the standard buffers of $\mathrm{pH} 7.0$ and 9.0. The DO probe was calibrated with sodium sulfite $(1 \mathrm{~N})$ and then saturated with oxygen to calibrate the range 0 to $100 \%$ respectively. The process parameters that were optimized in the shake-flask cultures were used for the bioreactor studies. The medium consisted of $2 \% \mathrm{w} / \mathrm{v}$ wheat bran, $2.5 \% \mathrm{w} / \mathrm{v}$ yeast extract, $0.25 \% \mathrm{w} / \mathrm{v}$ $\mathrm{NaCl}, 0.5 \% \mathrm{w} / \mathrm{v} \mathrm{NH}_{4} \mathrm{Cl}$, and $0.025 \% \mathrm{w} / \mathrm{v} \mathrm{MgSO}_{4} 7 \mathrm{H}_{2} \mathrm{O}$. The fermenter vessel along with the formulated medium was sterilized at $121^{\circ} \mathrm{C}$ at $15 \mathrm{psi}$ for $30 \mathrm{~min}$. Once the medium cooled to the process temperature, it was inoculated with actively growing culture of Bacillus licheniformis isolate $(10 \% \mathrm{v} / \mathrm{v})$. The process parameters were controlled at $\mathrm{pH}(6.0)$ and the culture temperature was maintained at $35^{\circ} \mathrm{C}$ and dissolved oxygen at $60 \%$ during the reactor run. The samples were withdrawn at $12 \mathrm{~h}$ intervals and analyzed for bacterial growth and xylanase activity.

\section{Results}

\section{Selection of carbon and nitrogen source}

The xylanase yield obtained with the preliminary experiments conducted for the selection of carbon sources has been given in Fig. 2. In these runs, the composition of the basal medium was kept constant while only the type 


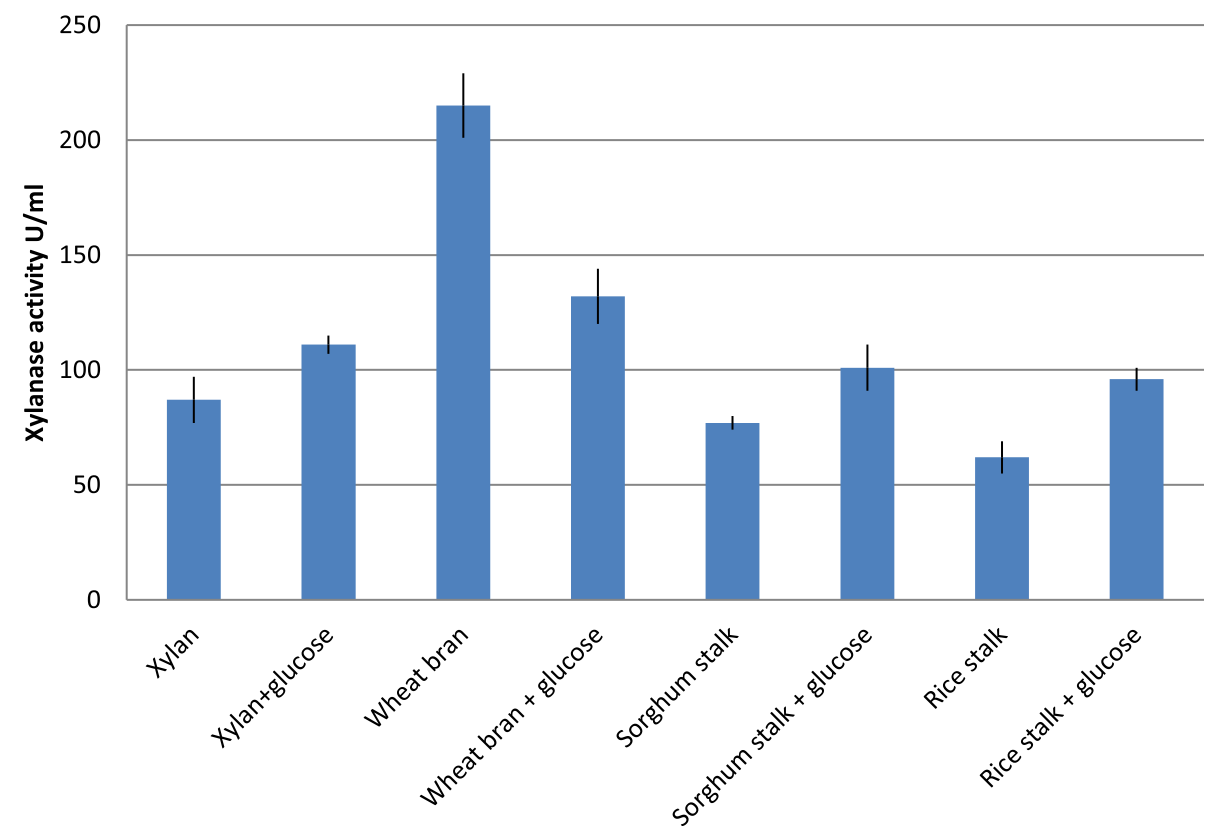

Fig. 2 Effect of different carbon sources on xylanase production

of agro-residue was varied. The concentration of agroresidue carbon source was fixed at $1 \% \mathrm{w} / \mathrm{v}$. The xylanase activity obtained after $72 \mathrm{~h}$ of culture was compared (Fig. 2).

It can be seen that the medium containing wheat bran as the sole carbon source showed highest xylanase production. Therefore, wheat bran was selected as the component of xylanase production medium. The substrates when formulated with glucose did not improve xylanase production to a significant extent. The xylanase yield obtained with the experiments conducted for the selection of nitrogen sources has been given in Fig. 3 .
Maximum xylanase production was obtained with yeast extract and hence it was chosen as the nitrogen source in the xylanase production medium.

The Taguchi optimization trials were conducted as per the design (Table 1) and xylanase activity for each trial run was determined as the output parameter (Fig. 4). The MINITAB statistical software package (Design Expert, Trial version) was used to generate and analyze the experimental design.

It is evident that the run 2 with factors setting at $\mathrm{pH}$ (6.0), temperature $\left(35^{\circ} \mathrm{C}\right)$, wheat bran $(2 \% \mathrm{w} / \mathrm{v})$, and

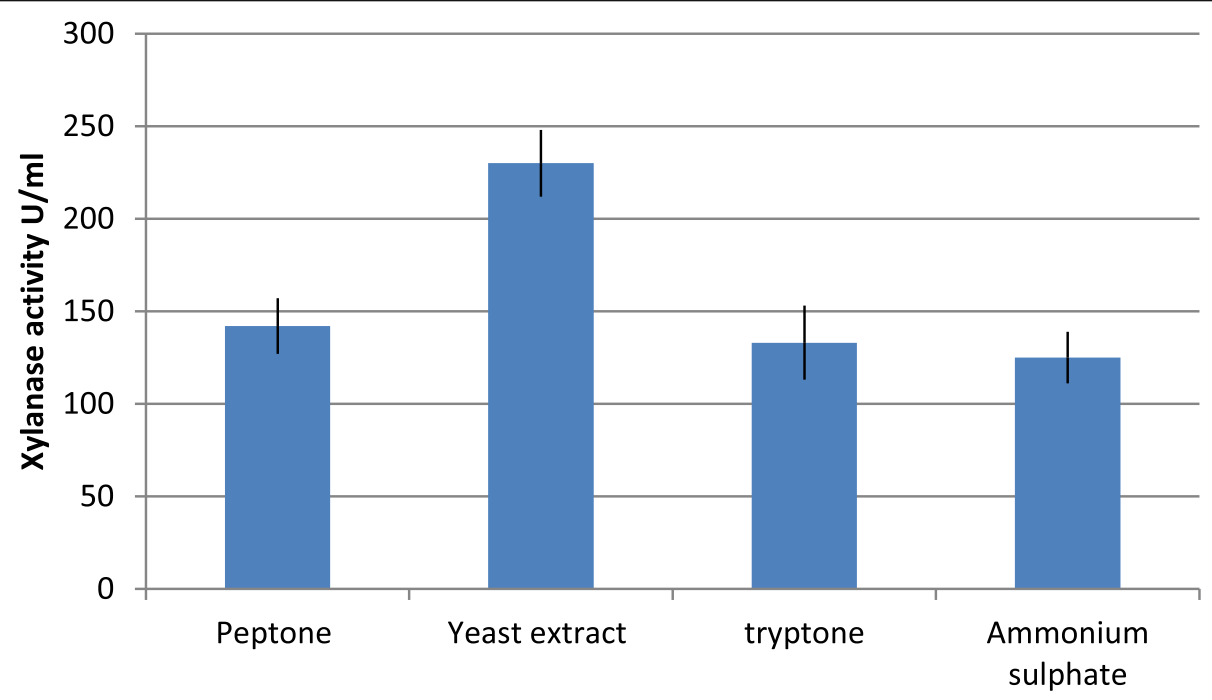

Fig. 3 Effect of different nitrogen sources on xylanase production 


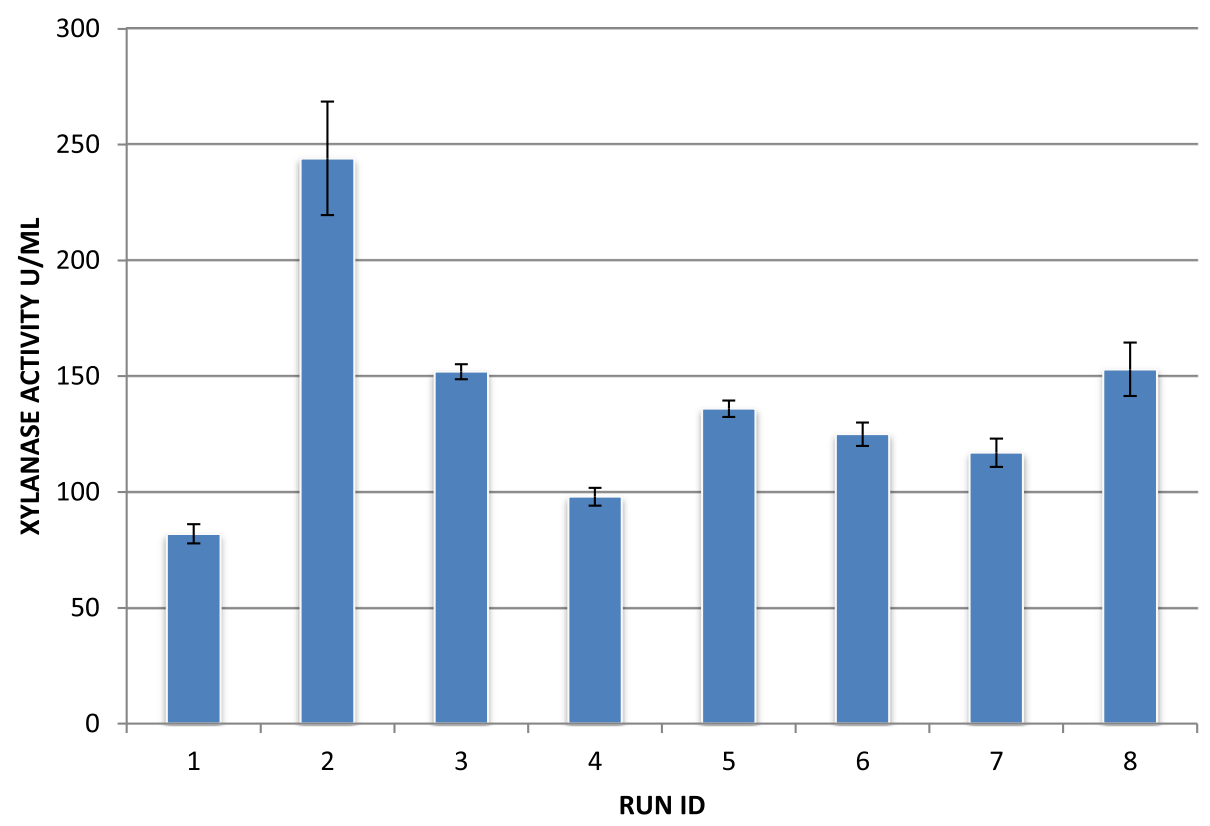

Fig. 4 Xylanase activity obtained in trial runs

yeast extract at $2.5 \%(\mathrm{w} / \mathrm{v})$ gave the highest xylanase production at $244 \mathrm{U} / \mathrm{ml}$. Whereas, the trial run 1 conducted with $\mathrm{pH}(6.0)$, temperature $\left(35^{\circ} \mathrm{C}\right)$, wheat bran $(0.5 \% \mathrm{w} /$ $\mathrm{v})$, and yeast extract at $1 \%(\mathrm{w} / \mathrm{v})$ resulted in the lowest yield of xylanase $(82 \mathrm{U} / \mathrm{ml})$. The large effect of the process parameters on the xylanase yield is thus evident from the results. Figures 5 and 6 illustrate for factorwise $\mathrm{S} / \mathrm{N}$ ratio and the main effects plots.

It is evident from the $\mathrm{S} / \mathrm{N}$ and the main effects plots that the concentration of yeast extract had the greatest

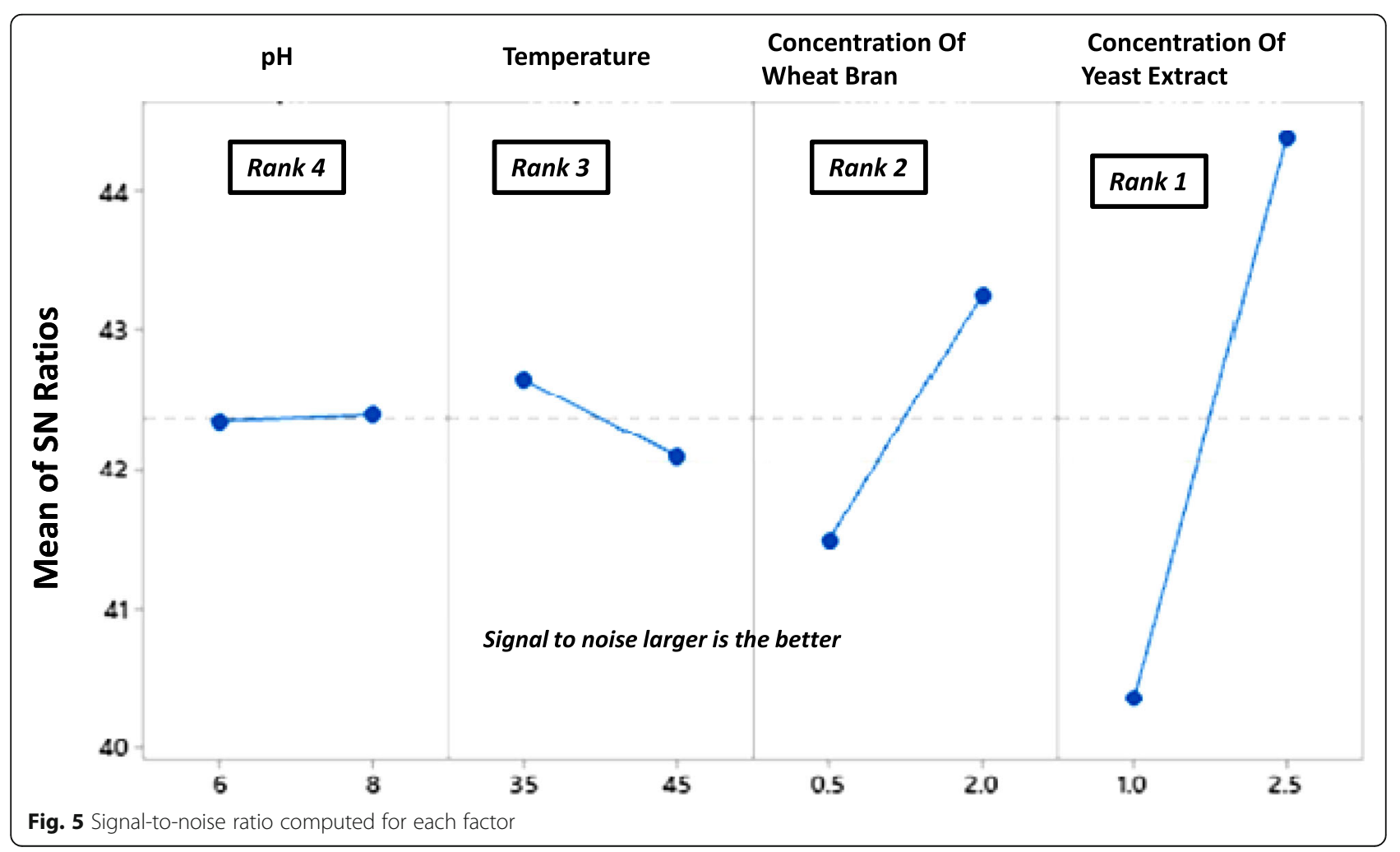




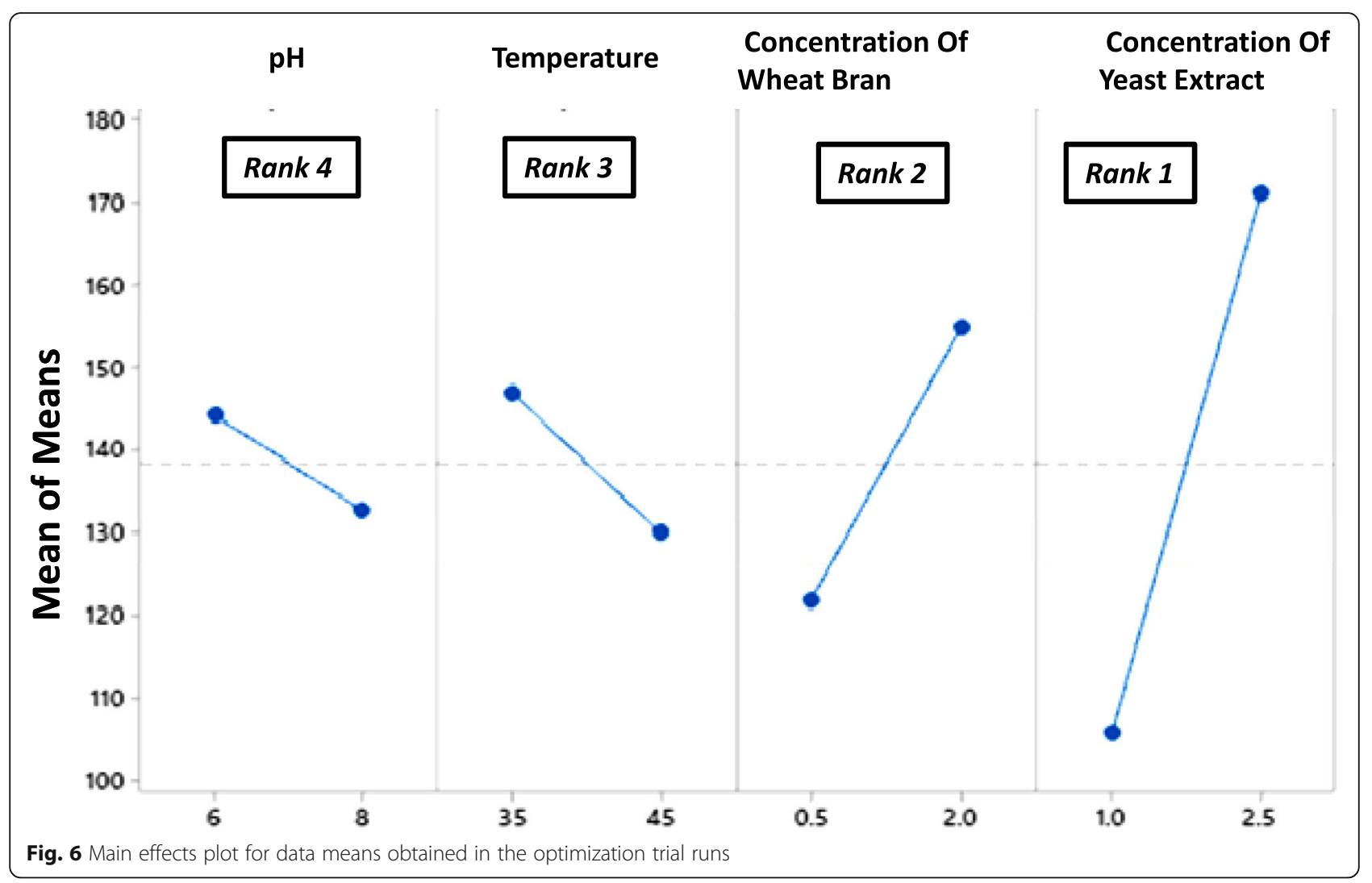

effect on xylanase production followed by wheat bran concentration, culture temperature, and medium $\mathrm{pH}$. The factor yeast extract concentration with greatest delta $(\nabla)$ value was assigned rank 1 depicting its highest effect on xylanase. Similarly, concentrations of wheat bran and incubation temperature rank second and third respectively. The initial media $\mathrm{pH}$ had the least effect on xylanase production and was assigned rank 4 . In order to determine the statistical significance of each factor on xylanase production, analysis of variance (ANOVA) was carried out (Table 2). It was observed that the factors $\mathrm{pH}$ and temperature did not contribute significantly to

Table 2 ANOVA table for means

\begin{tabular}{lllllll}
\hline Source & DF & Seq SS & Adj SS & Adj MS & $\boldsymbol{F}$ & $\boldsymbol{P}$ \\
\hline $\mathrm{pH}$ & 1 & 258.0 & 258.0 & 258.0 & 0.14 & 0.729 \\
Temperature & 1 & 580.5 & 580.5 & 580.5 & 0.33 & 0.608 \\
Wheat bran & 1 & 2189.4 & 2189.4 & 2189.4 & 1.23 & 0.349 \\
Yeast extract & 1 & 8562.7 & 8562.7 & 8562.7 & 4.80 & 0.116 \\
Residual error & 3 & 5349.1 & 5349.1 & 1783.0 & & \\
Total & 7 & $16,939.7$ & & & & \\
Wheat bran & 1 & 2189 & 2189 & 2189 & 1.77 & 0.241 \\
Yeast extract & 1 & 8563 & 8563 & 8563 & 6.92 & 0.047 \\
Residual error & 5 & 6188 & 6188 & 1238 & & \\
Total & 7 & 16,940 & & & & \\
\hline
\end{tabular}

xylanase production. In order to increase the accuracy of the model the effects of these were pooled (Table 3).

Linear regression model was used to fit the experimental data and to identify the relevant model terms. The regression equation obtained was

Xylanase concentration $=138.40-16.54 \times$ wheat bran concentration $-32.72 \times$ yeast extract concentration

Finally, the optimized settings for each parameter were obtained as given in the Table 3 .

The validation experiments were carried out according to the following factor settings as given in Table 4 .

It can be observed from Table 4 that the model could accurately predict the xylanase production at different settings of the factors and hence it could be validated.

\section{Bioreactor studies}

The bioreactor was operated using standard operating procedure as mentioned in the "Methods" section. The process parameters were controlled at optimized values of pH 6.0 and temperature $35^{\circ} \mathrm{C}$. The agitator was operated at 150 RPM and DO was controlled at $60 \%$. The xylanase activity and optical density at $620 \mathrm{~nm}$ was

Table 3 Optimized settings for each factor

\begin{tabular}{llll}
\hline $\mathrm{pH}$ & $\begin{array}{l}\text { Temperature } \\
\left({ }^{\circ} \mathrm{C}\right)\end{array}$ & $\begin{array}{l}\text { Concentration of } \\
\text { wheat bran }(\% \mathrm{w} / \mathrm{v})\end{array}$ & $\begin{array}{l}\text { Concentration of yeast } \\
\text { extract }(\% \mathrm{w} / \mathrm{v})\end{array}$ \\
\hline 6 & $35^{\circ} \mathrm{C}$ & 2 & 2.5 \\
\hline
\end{tabular}


Table 4 Factor settings for validation experiment and the predicted and actual xylanase activity

\begin{tabular}{lllll}
\hline SN & $\begin{array}{l}\text { Concentration } \\
\text { of wheat bran } \\
(\% \text { w/v) }\end{array}$ & $\begin{array}{l}\text { Concentration } \\
\text { of yeast extract } \\
(\% \text { w/v) }\end{array}$ & $\begin{array}{l}\text { Predicted } \\
\text { xylanase activity } \\
\text { by the model }\end{array}$ & $\begin{array}{l}\text { Xylanase } \\
\text { activity } \\
\text { obtained }\end{array}$ \\
\hline 1 & 0.5 & 1 & 97.41 & 89 \\
2 & 1 & 2 & 220.38 & 202 \\
3 & 2 & 2.5 & 253.28 & 244 \\
\hline
\end{tabular}

measure during the reactor run. Figure 7 gives the time course of growth and xylanase production in the batch stirred tank reactor for two different reactor runs.

It could be observed that peak xylanase activity was achieved in $60 \mathrm{~h}$ in the bioreactor which is much faster as compared to the shake-flask experiments where the peak activity is obtained in $72 \mathrm{~h}$ [15]. Moreover, the enzyme concentration obtained was much higher than the shake flask cultures.

\section{Discussion}

Every organism has unique medium requirements that would direct its cellular machinery toward the production of the desired compound. The type and concentration of media components and process parameters such as the rate of agitation, $\mathrm{pH}$, and culture temperature have a significant effect on bioprocess yields. The concentration of carbon and nitrogen are often found to be limiting in the bioprocesses due to their higher consumption rates. It has been elucidated by several studies that bacterial xylanase production is repressed in the presence of easily available carbon sources such as glucose due to carbon catabolite repression and induced by the availability of xylan (xylooligosaccharides) [12]. Irfan et al. [9] carried out optimization of process parameters for xylanase from an isolate of $\mathrm{Ba}$ cillus sp. They concluded that $\mathrm{pH}$ (range tested 4-10), temperature $\left(25-50{ }^{\circ} \mathrm{C}\right)$, substrate concentration $(0.5$ to $3 \%$ $\mathrm{w} / \mathrm{v})$, and inoculum size $(0.5$ to $3 \% \mathrm{v} / \mathrm{v})$ affected xylanase production significantly. The optimum parameter levels were found to be $\mathrm{pH} 8$, temperature $35-40{ }^{\circ} \mathrm{C}$ (for Bacillus subtilis and Bacillus licheniformis strains) $2 \% \mathrm{w} / \mathrm{v}$ and inoculum size $2-3 \%$ v/v. Statistical optimization of xylanase production from Bacillus tequilensis strain using response surface methodology was carried out by Khusro et al. [11] They reported the optimized component levels as birchwood xylan $(1.5 \% \mathrm{w} / \mathrm{v})$, yeast extract $(1 \% \mathrm{w} / \mathrm{v})$, incubation temperature $\left(40^{\circ} \mathrm{C}\right)$, and time period $(24 \mathrm{~h})$. Shanthi and Royman [20] attempted the optimization of process parameters for xylanase production by two strains of Bacillus and reported that the maximum xylanase levels were obtained at $\mathrm{pH} 9.0,55^{\circ} \mathrm{C}$ for Bacillus sp. MCC2728 and $50{ }^{\circ} \mathrm{C}$ for Bacillus sp. MCC2727, 5\% v/v inoculum, and agitation speed $(150 \mathrm{rpm})$. Yeast extract and peptone were reported to be the best nitrogen sources and wheat bran was found to be the best carbon source. Our previous studies on crude xylanase had showed an optima of $\mathrm{pH}$ 6.5 (enzyme stability range from 6-8) and temperature optima of $70{ }^{\circ} \mathrm{C}$ (stable range $40-80{ }^{\circ} \mathrm{C}$ ) [15]. Based on these insights, concentrations of the carbon and nitrogen sources, initial $\mathrm{pH}$ of the culture medium, and culture temperature were chosen to be optimized for the maximization of xylanase production.

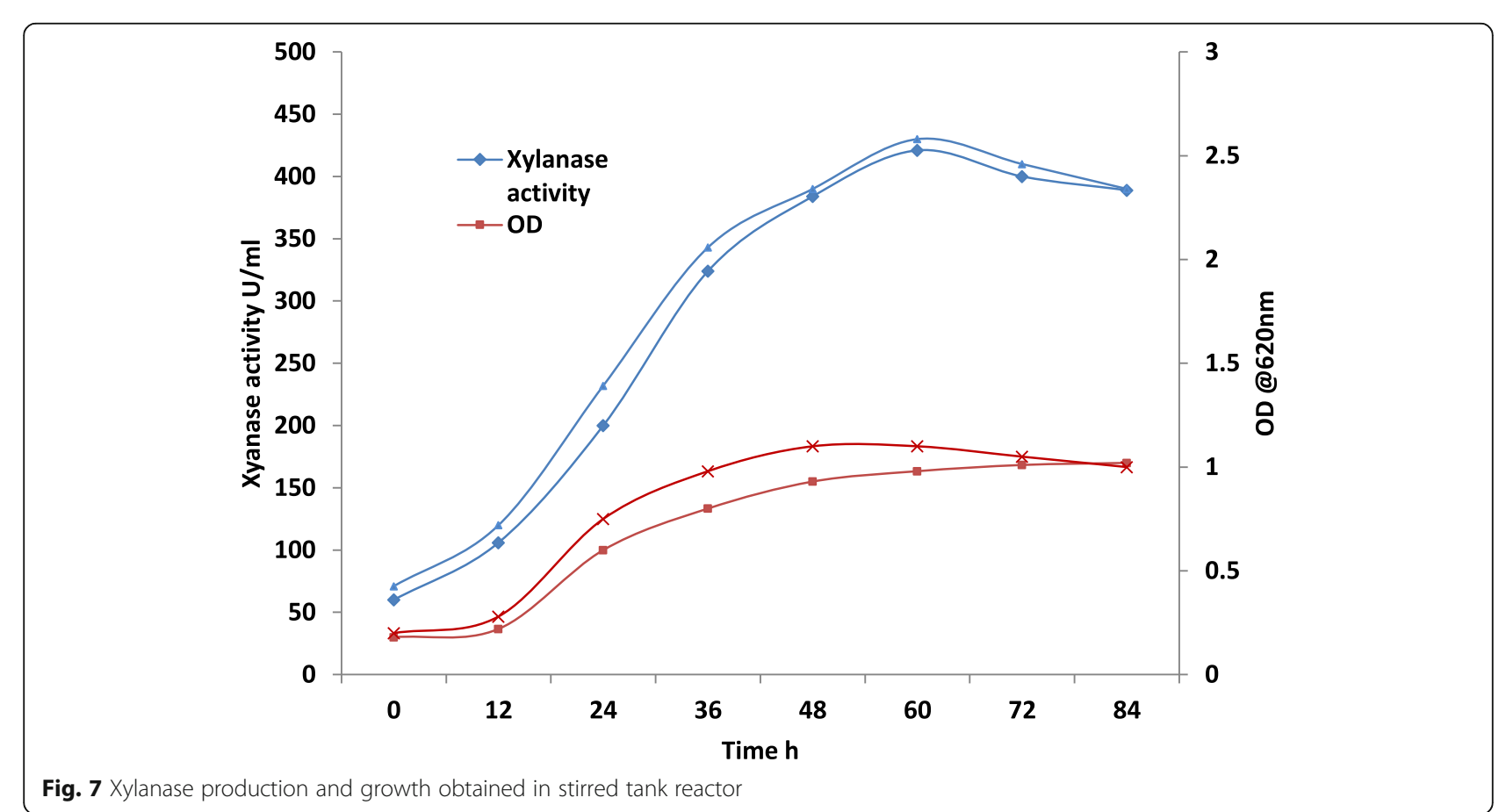


Locally available agro-residues such as xylan, wheatbran, sorghum stalk, and rice stalk were used. These residues provide xylan for the induction of xylanase production. The selection of wheat-bran as the carbon source and yeast extract as the nitrogen source was made on the basis of comparison of xylanase production obtained with varying the type of agro-residue and nitrogen sources only (Figs. 2 and 3).

The utility of the Taguchi robust design for optimization of process parameters is well-known as shown by several recent reports of numerous processes that have been optimized using this design $([4,7]$, and [18]), and the results from the present study also consolidate the applicability of the strategy. The Taguchi design was applied and analyzed, the optimized conditions given by the model were as follows: (i) $\mathrm{pH} 6$, (ii) culture temperature $35^{\circ} \mathrm{C}$, (iii) concentration of xylan $2 \% \mathrm{w} / \mathrm{v}$, and (iv) concentration of wheat bran $2.5 \% \mathrm{w} / \mathrm{v}$. The model developed for the relation of factor levels to xylanase could efficiently predict the xylanase production as given by the results of the validation runs. The study revealed that xylanase production depended on the concentration of yeast extract and xylan whereas $\mathrm{pH}$ and culture temperatures did not affect the production to significant extent in the particular experimental range. Kumar et al. [14] also found the influence of wheat bran and yeast extract concentration on xylanase production by alkaliphilic Bacillus pumilus strain. The strategy exemplifies an efficient method for reducing the time required for upstream process optimization. Higher xylanase yield and reduction of batch time was achieved in the reactor. This is likely due to the effective control of bioprocess parameters in the reactor as compared to the shake flask conditions. Peak growth was achieved at $48 \mathrm{~h}$ of culture in the reactor, whereas the peak xylanase activity was obtained in $60 \mathrm{~h}$ of reactor run. In the future work, production process would be optimized exclusively using bioreactor keeping in view the other important control parameters such as DO, rate of agitation, and antifoaming agent. Xylanase activity fell toward the end of the reactor run which is likely due to the proteolytic degradation. Holland et al. [8] reported the degradation of xylanases by extracellular proteases and recommend use of protease inhibitors in the medium.

\section{Conclusion}

The present paper gives an effective and simple strategy for the process optimization of xylanase production from a newly isolated Bacillus licheniformis strain with promising xylanolytic potential. Medium optimization was successful in achieving more than threefold increase in xylanase production using optimized conditions. The production was scaled up to $2.5 \mathrm{~L}$ working volume lab scale reactor, employing the parameters as optimized in the shake flask experiments. A high xylanase titer of 400 $\mathrm{U} / \mathrm{ml}$ could be achieved in less than $60 \mathrm{~h}$ of culture in the reactor. This paper describes a simple and time efficient strategy to bring about fold increase in xylanase production by the optimization of process parameters.

\begin{abstract}
Abbreviations
OFAT: One factor at a time; DNSA: 3, 5-dinitrosalicylic acid; S/N ratio: Signal to noise ratio; ANOVA: Analysis of variance; Coef: Coefficient; SE

Coeff: Standard error of the coefficient; T: Test statistic for Student's $t$ distribution; P: P value; DF: Degree of freedom; Seq SS: Sequential sums of squares; Adj SS: Adjusted sum of squares; Adj MS: Adjusted mean squares
\end{abstract}

\section{Acknowledgements}

We acknowledge the funds and facilities provided by Molecular Biosciences Research Cluster, Manav Rachna International Institute of Research and Studies for this project.

\section{Authors' contributions}

Both authors (GM and SSC) have read and approved the manuscript. GM: Worked in the project and generated and analyzed the data. She also contributed in manuscript preparation. SSC: She was responsible for the conceptualization, execution, supervision, data generation and analysis. She also carried out manuscript preparation and review was carried out.

\section{Funding}

The funding for the research was provided by Molecular Biosciences Research Cluster, Manav Rachna International Institute of Research and Studies.

\section{Availability of data and materials}

The datasets used and/or analyzed during the current study are available from the corresponding author on reasonable request.

Ethics approval and consent to participate Not applicable

\section{Consent for publication}

Not applicable

\section{Competing interests}

The authors declare that they have no competing interests.

Received: 25 June 2020 Accepted: 12 October 2020

Published online: 22 October 2020

\section{References}

1. Adhyaru DN, Bhatt NS, Modi HA (2015) Optimization of upstream and downstream process parameters for cellulase-poor-thermo-solvent-stable xylanase production and extraction by Aspergillus tubingensis FDHN1. Bioresour Bioprocess 2. https://doi.org/10.1186/s40643-014-0029-1

2. Ashok A, Doriya K, Rao JV et al (2019) Microbes producing L-asparaginase free of glutaminase and urease isolated from extreme locations of Antarctic soil and moss. Sci Rep 9:1-10. https://doi.org/10.1038/s41598-018-38094-1

3. Bailey MJ, Biely P, Poutanen K (1992) Interlaboratory testing of methods for assay of xylanase activity. J Biotechnol 23:257-270

4. Chenthamarakshan A, Parambayil N, Miziriya N, Soumya PS, Lakshmi MK, Ramgopal A, Dileep A, Nambisan P (2017) Optimization of laccase production from Marasmiellus palmivorus LA1 by Taguchi method of design of experiments. BMC biotechnol 17(1):12

5. Dhiman S, Chapadgaonkar SS (2013) Optimization of lipase production medium for a bacterial isolate. Inter J Chem Technol Res. 5:2837-2843

6. Elegbede JA, Lateef A (2019) Optimization of the production of xylanases in corncob-based media by Aspergillus niger and Trichoderma longibrachiatum using Taguchi approach. Acta Biol Szeged 63:51-58. https://doi.org/10. 14232/abs.2019.1.51-58

7. El-Moslamy SH, Elkady MF, Rezk AH, Abdel-Fattah YR (2017) Applying Taguchi design and large-scale strategy for mycosynthesis of nano-silver from endophytic Trichoderma harzianum SYA. F4 and its application against phytopathogens. Scientific Reports 7:45297 
8. Holland AT, Danson MJ, Bolhuis A (2019) Inhibition of extracellular proteases improves the production of a xylanase in Parageobacillus thermoglucosidasius. BMC biotechnology. 19(1):17

9. Irfan M, Asghar U, Nadeem M, Nelofer R, Syed Q (2016) Optimization of process parameters for xylanase production by Bacillus sp. in submerged fermentation. J Radiation Res Appl Sci 9(2):139-147

10. Khaparde SS, Roychoudhury PK, Gomes J, Mukhopadhyay A (2008) External modulation of HT-1080 human fibrosarcoma cells improves urokinase production. Biotechnol Prog 24. https://doi.org/10.1002/btpr.21

11. Khusro A, Kaliyan BK, Al-Dhabi NA, Arasu MV, Agastian P (2016) Statistical optimization of thermo-alkali stable xylanase production from Bacillus tequilensis strain ARMATI. Electronic J Biotechnol 22:16-25

12. Kobakhidze A, Asatiani M, Kachlishvili E, Elisashvili V (2016) Induction and catabolite repression of cellulase and xylanase synthesis in the selected white-rot basidiomycetes. Ann Agrar Sci 14:169-176. https://doi.org/10. 1016/j.aasci.2016.07.001

13. Kumar M, Singh A, Beniwal V, Salar RK (2016) Improved production of tannase by Klebsiella pneumoniae using Indian gooseberry leaves under submerged fermentation using Taguchi approach. AMB Express 6:1-11. https://doi.org/10.1186/s13568-016-0217-9

14. Kumar L, Kumar D, Nagar S, Gupta R, Garg N, Kuhad RC, Gupta VK (2014) Modulation of xylanase production from alkaliphilic Bacillus pumilus VLK-1 through process optimization and temperature shift operation. 3. Biotech. 4(4):345-356

15. Malhotra G, Chapadgaonkar SS (2020) Production of thermo-alkali stable xylanase from Bacillus licheniformis isolated from natural hot water geyser. $J$ Miroscopy Ultrastructure (in press)

16. Malhotra G, Chapadgaonkar SS (2018) Production and applications of xylanases - an overview. Biotechnologia 99. https://doi.org/10.5114/bta. 2018.73562

17. Prakasham RS, Rao CS, Rao RS et al (2005) Optimization of alkaline protease production by Bacillus sp. using Taguchi methodology. Appl Biochem Biotechnol 120:133-144. https://doi.org/10.1385/ABAB:120:2:133

18. Pundir R, Chary GH, Dastidar MG (2018) Application of Taguchi method for optimizing the process parameters for the removal of copper and nickel by growing Aspergillus sp. Water resources and industry. 20:83-92

19. Ramanjaneyulu G, Rajasekhar Reddy B (2016) Optimization of xylanase production through response surface methodology by Fusarium sp. BVKT R2 isolated from forest soil and its application in saccharification. Front Microbiol 7:1450. https://doi.org/10.3389/fmicb.2016.01450

20. Shanthi V, Roymon MG (2018) Isolation, identification and partial optimization of novel xylanolytic bacterial isolates from Bhilai-Durg Region, Chhattisgarh, India. Iran J Biotechnol 16(3). https://doi.org/10.15171/ijb.1333

21. Uysal E, Akcan N, Baysal Z, Uyar F (2011) Optimization of a-amylase production by Bacillus subtilis RSKK96: using the Taguchi experimental design approach. Prep Biochem Biotechnol 41:84-93. https://doi.org/10. 1080/10826068.2010.534333

\section{Publisher's Note}

Springer Nature remains neutral with regard to jurisdictional claims in published maps and institutional affiliations.

\section{Submit your manuscript to a SpringerOpen ${ }^{\circ}$ journal and benefit from:}

- Convenient online submission

- Rigorous peer review

- Open access: articles freely available online

- High visibility within the field

- Retaining the copyright to your article

Submit your next manuscript at $\boldsymbol{\nabla}$ springeropen.com 